\title{
RAPID PHOTO-ASSISTED FORMING GAS ANNEAL (FGA) FOR HIGH QUALITY SCREEN-PRINTED CONTACTS FOR SILICON SOLAR CELLS
}

\author{
A. Ebong, M. Hillali and A. Rohatgi \\ School of Electrical and Computer Engineering, Georgia Institute of Technology, 777 Atlantic Drive, GA \\ 30332-0250 \\ E-mail- aebong@ee.gatech.edu ; Fax-404894 4832; Tel - 4048941884
}

\begin{abstract}
Formation of low-cost high-quality contacts is the key to cost-effective silicon solar cells. Screen-printing is widely used in Industry because it is simple, low-cost and rapid. However, cost and throughput gains are attained at the expense of performance. Fill factors of most commercial cells are in the range of $0.68-75$ for single crystalline material. This paper shows that a rapid $400^{\circ} \mathrm{C} / 0.5-3 \mathrm{~min}$ photo-assisted anneal in a forming gas ambient can raise the fill factor (FF) of screen-printed (SP) single and multicrystalline $(\mathrm{mc})$ Si cells from $\sim 0.70$ to $\sim 0.77$ and 0.76 , respectively. Dark I-V analysis showed that this results from a decrease in series resistance by a factor of 2 to 4 . Thus initial belt firing conditions can be tailored $\left(\geq 700^{\circ} \mathrm{C}\right)$ to first prevent the junction shunting, which generally results in high series resistance $\left(R_{s}\right)$, and then the rapid photo-assisted anneal in forming gas ambient can be used to reduce the resistive losses for achieving high FF without much junction shunting. The LBIC analysis on multicrystalline silicon shows that a 30 -second forming gas anneal in RTP not only reduces the glass frit at the silicon/silver interface but also enhances hydrogenation of bulk defects.
\end{abstract}

\section{INTRODUCTION}

Screen-printed (SP) contact technology is a rapid and cost-effective contacting method that is consistent with the requirements for high volume manufacturing. Other advantages of the screen printing technology include robustness of the equipment, low amount of chemical waste and simplicity. The use of rapid thermal processing (RTP), which uses banks of tungsten-halogen lamps to illuminate and rapidly heat silicon wafers, in conjunction with screen-printed contacting scheme can significantly reduce the processing cost. In this study belt line processing (BLP) has been used for diffusions and initial contact firing but the final contact annealing is performed in a single wafer RTP system.

In 1982 Okamoto et al [1] proposed the use of light source of high intensity for diffusion as well as back surface field (BSF) formation and front metal contacts. Cheek et al [2] in 1984 used the BLP for emitter formation and firing of the screen-printed metal contacts (both AL-BSF and front $\mathrm{Ag}$ fingers). Screen-printed cell efficiencies of about $13 \%$ and $11.6 \%$, respectively, were reported on $\langle 111\rangle$ and $\langle 100\rangle$ oriented single crystalline silicon and $9.6 \%$ on multicrystalline silicon. Sivoththaman et al $[3,4]$ reported BLP screen-printed cells with $15.6 \%$ and $14.5 \%$ efficiencies on $\mathrm{CZ}$ and multi-crystalline silicon, respectively. Goris et al [6] also reported a $14 \%$ efficiency on $\mathrm{mc}-\mathrm{Si}$ solar cell fabricated by the use of IR belt furnace for emitter formation and firing of the screen-printed metal contacts. In each of these cases, the fill factor ranged from $67 \%$ to $74 \%$ on multi-crystalline and $70-75.7 \%$ on single crystalline SP cells.

The primary fill factor (FF) loss mechanisms associated with SP metallization are grid line resistance, contact resistance, and junction leakage and shunting. The grid line resistivity and the contact resistance both depend on the contact firing cycle and the material quality of the conductor paste. It is possible that a particular firing cycle can lead to significant "bleed-out" [2] of glass frit from the Ag paste to the metal-Si interface, which in turn can lead to high contact resistance immediately after firing resulting in low FFs of $0.500-0.650$. A short time (20-30 minutes) $400^{\circ} \mathrm{C}$ forming gas anneal (FGA) in conventional furnace has been used [5] to effectively reduce the contact resistance at the metal-Si interface and increase the FFs to the $0.785-0.795$ range for single crystalline silicon cells. In this paper we show that only a $0.5-3-$ minute photoassisted contact anneal at $400^{\circ} \mathrm{C}$ in a forming gas ambient can accomplish the same task, and improve the fill factor from 0.68 to 0.76 for $\mathrm{mc}$-Si and from 0.73 to 0.77 for single crystalline silicon.

\section{EXPERIMENTAL}

The process sequence adopted in this study includes emitter formation by spin-on, bake, and 6 -min belt line diffusion at $925^{\circ} \mathrm{C}$. This resulted in a $40-45 \Omega / \square$ emitter with a junction depth of about $0.25 \mu \mathrm{m}$ and peak concentration of $2.6 \times 10^{19}$ atoms $/ \mathrm{cm}^{3}$. After phosphorus glass removal and $D \mid$ water rinse, a single layer PECVD $\mathrm{SiN}$ antireflection coating was deposited on the front at $300^{\circ} \mathrm{C}$. This was followed by screen-printing of $\mathrm{Al}$ on the back and a 2 min drive-in at $860^{\circ} \mathrm{C}$ in the belt furnace to form a very effective Al back surface field. A silver grid was screen-printed on top of $\mathrm{SiN}$ and then fired through $\mathrm{SiN}$ for two different firing cycles (slow and spike) to study the impact of "bleed out" effect of glass frit on series resistance and fill factor. Firing cycles involving a belt speed of $15-30 \mathrm{inch} / \mathrm{min}$ in conjunction with low firing temperatures $\left(700-800^{\circ} \mathrm{C}\right)$ are referred to as slow firing and belt speeds of $60-75 \mathrm{inch} / \mathrm{min}$ with firing temperatures of $800-900^{\circ} \mathrm{C}$ are referred to as spike firing in this study.

\section{RESULTS AND DISCUSSION}

Since the primary fill factor loss mechanisms associated with SP metallization include contact/series resistance $\left(R_{s}\right)$, shunt resistance $\left(R_{s h}\right)$, and junction leakage $\left(J_{02}\right.$ and $\mathrm{n})$, detailed dark $\mathrm{I}-\mathrm{V}$ measurements were performed to decouple $R_{s}, R_{s h}, J_{02}$ and $n_{2}$ values by the measured I- $V$ fit to the double exponential diode model. Figs. 1-3 show the 
$R_{s}, F F, J_{02}$ and $n_{2}$ values for the two firing schemes before and after a 3 minute contact anneal in forming gas ambient using the RTP system. Figures 4 and 5 show the effect of a 15 minute contact anneal in forming gas ambient on fill factor and series resistance, using a conventional tube furnace. The cells were fabricated on $2.1 \Omega$-cm mc-Si from Eurosolare (2euo), $0.8 \Omega-\mathrm{cm} \mathrm{mc}-\mathrm{Si}$ from Bayer Solar (bmc), 1.3 $\Omega-\mathrm{cm} F Z$ and CZ silicon.

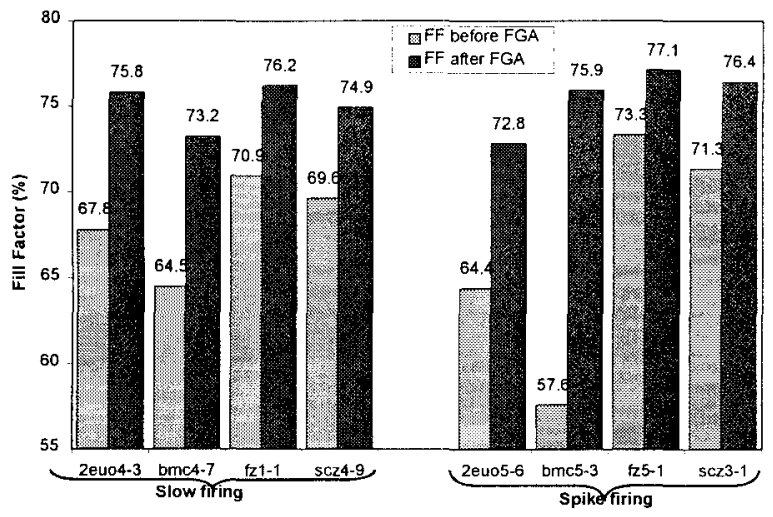

Fig. 1: The effect of 3-minute photo-assisted FGA on fill factor for slow and spike fired cells

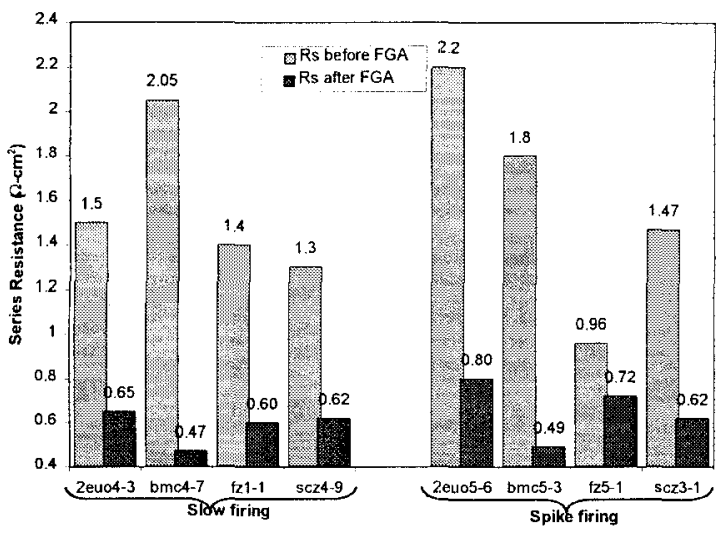

Fig. 2: The effect of 3-minute photo-assisted FGA on series resistance $\left(R_{\mathrm{s}}\right)$ for slow and spike fired cells

\section{EFFECT OF PHOTO-ASSISTED FGA ON MG-Si SOLAR CELLS}

Both slow and spike-fired cells gave low FFs (58-68\%) before the FGA treatment due to high series resistance values in the range of 1.5 to $2.2 \Omega-\mathrm{cm}^{2}$. It should be noted that the shunt resistance for all the cells was greater than $1000 \Omega-\mathrm{cm}^{2}$. After the 3-minute FGA in RTP, the FF improved significantly for the two sets of cells, Fig. 1. For slow-fired cells, 2euo4-3 and bmc4-7, FF improved from 0.68 to 0.76 and 0.65 to 0.74 , respectively. This short time FGA is believed to induce a frit reduction reaction that returns the interfacial layer to a low-resitance state,

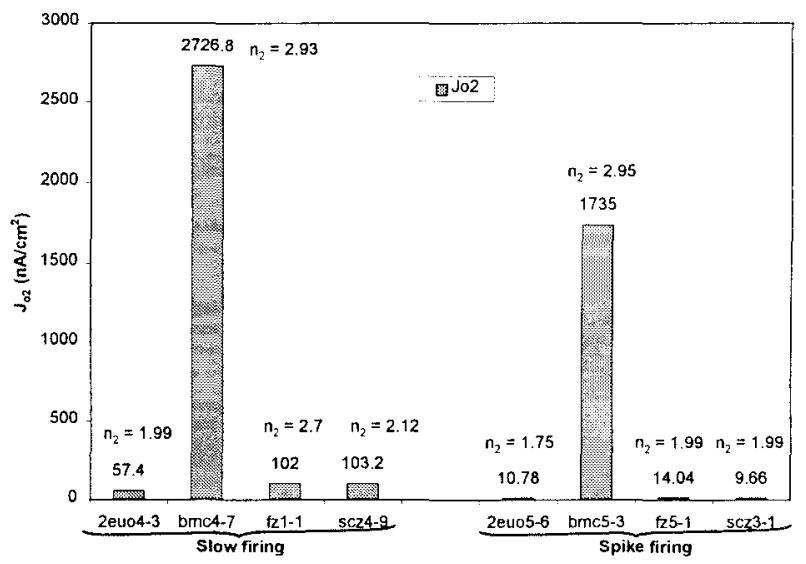

Fig. 3: The effect of 3-minute photo-assisted FGA on $\mathrm{J}_{02}$ and $\mathrm{n}_{2}$ for slow and spike fired cells.

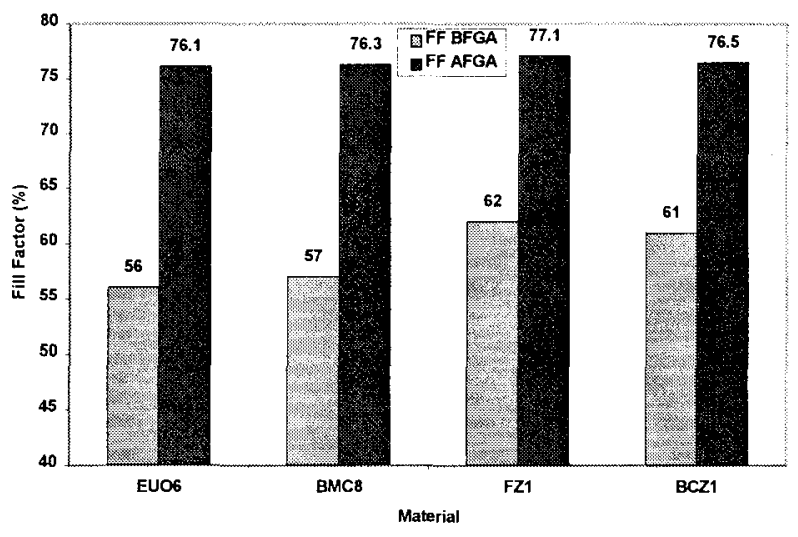

Fig. 4: The effect of 15-minute CFP FGA on fill factor for slow fired cells.

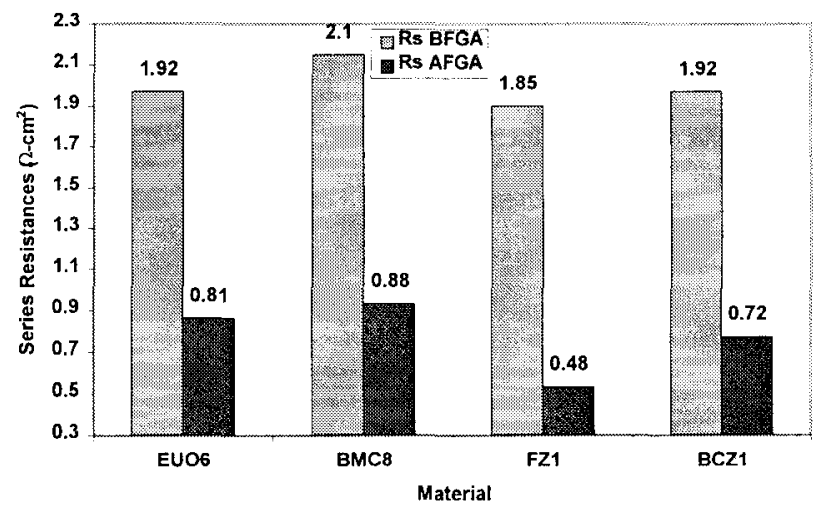

Fig. 5: The effect of 15-minute CFP FGA on series resistance $\left(R_{s}\right)$ for slow fired cells

resulting in low series resistance $\left(0.47-0.65 \Omega-\mathrm{cm}^{2}\right)$, Fig. 2 . The FF for the spike fired cells, 2euo5-6 and bmc5-3, also improved from 0.64 to 0.73 and 0.58 to 0.754 , Fig. 1. The $\mathrm{J}_{02}$ values for slow and spike-firing conditions for the two 
Eurosolare cells were quite respectable and comparable. However, in the case of bayer mc-Si, the slow-fired cell gave $J_{02}$ values, which were quite high. This suggests that same firing condition can lead to different degree of pastedefect interaction in mc-Si materials. Thus a gentler firing condition (lower temperature or shorter time) should be selected for Bayer mc-Si to prevent junction leakage due to paste-defect interaction. However, lower temperature and shorter firing time generally leads to high contact resistance. This study shows that a low temperature rapid FGA can reduce this series resistance and provide a means for achieving high fill factors without significant junction shunting and series resistance.

\section{EFFECT OF PHOTO-ASSISTED FGA ON SINGLE CRYSTALLINE SOLAR CELLS}

Fig. 1 shows that the FFs for both the slow and spike fired single crystal cells were also low $(0.70-0.73)$ before the FGA. The series resistance values ranged from $0.96-1.92$ $\Omega-\mathrm{cm}^{2}$, Fig. 2 or Fig. 5 , before the FGA in RTP or CFP. The shunt resistances were quite respectable for high FFs before and after FGA. Figs. 1 an 2 as well as 4 and 5 show that the series resistance reduced to 0.60-0.62 after FGA and led to a fill factor of 0.771 on FZ cells. However, the $J_{02}$ values for the slow fired cells were one order of magnitude higher than the spike fired cells, Fig. 3, which resulted in slightly lower fill factor for the slow fired cells.

\section{LIGHT BEAM INDUCED CURRENT (LBIC) ANALYSIS FOR BULK DEFECT PASSIVATION DUE TO FGA}

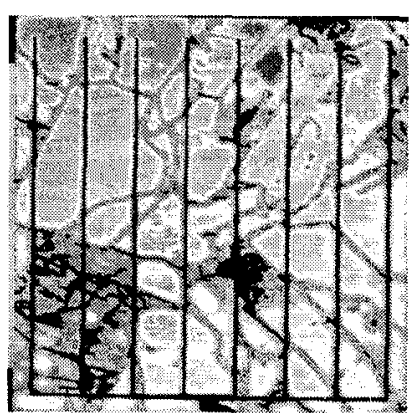

Fig. 6a: Cell Bmc2 before $F G A$. $F F=0.57$

Color legend

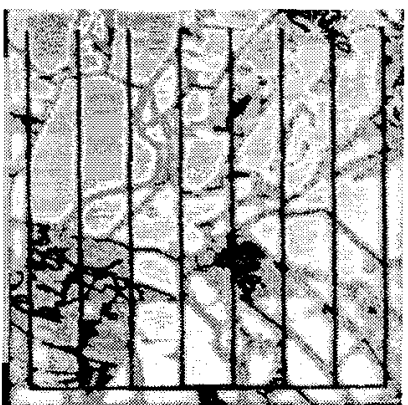

Fig. 6b: Cell Bmc2 after 30second photo-assisted FGA. $\mathrm{FF}=0.744$

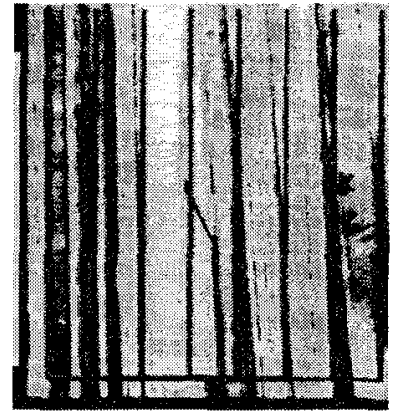

Fig. 6c: Cell T7 before $F G A . F F=0.47$

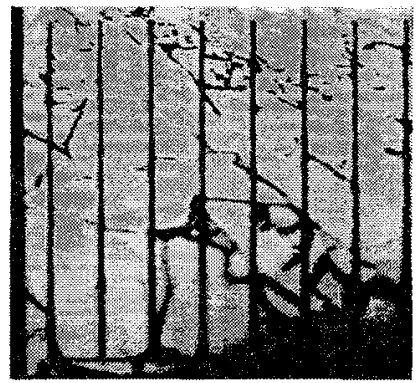

Fig. 6e: Cell Eu2-3 before $F G A . F F=0.57$

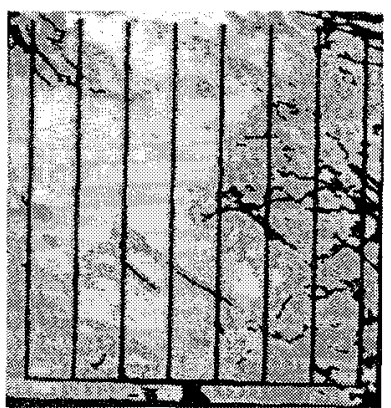

Fig. 7a: Cell Eu2-6 before $F G A$. FF $=0.600$

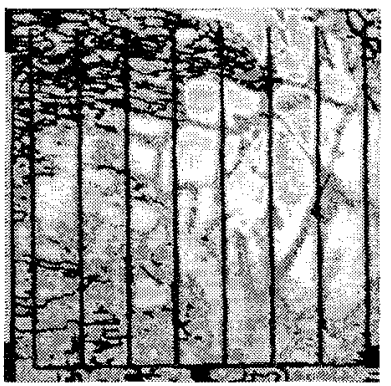

Fig. 8a: Cell Eu2-9 before $F G A$. $F F=0.598$

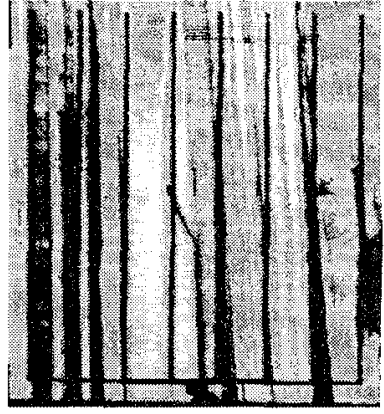

Fig. 6d: Cell T7 after 30-second photo-assisted FGA. FF=0.744

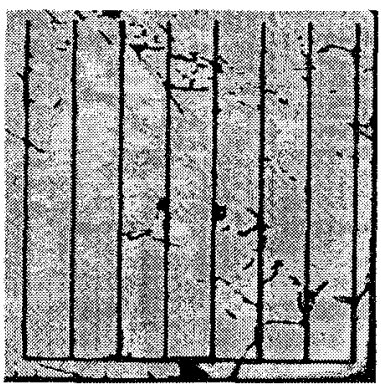

Fig. 6f: Cell Eu2-3 after 30second photo-assisted $F G A$. $F F=0.719$

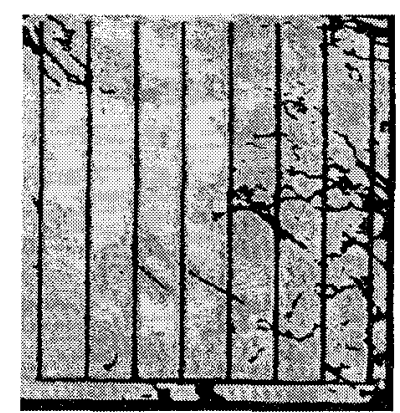

Fig. 7b: Cell Eu2-6 after $15-\mathrm{min} F G$. $F F=0.731$

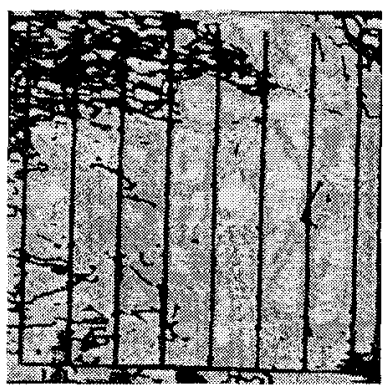

Fig. 8b: Cell Eu2-9 after $3-\min F G A$. $F F=0.721$ from the silicon nitride film during the cell contact firing 
the $400^{\circ} \mathrm{C}$ forming gas anneal process, the temperature is much lower for the hydrogenation of the bulk defect. In order to ascertain whether the forming gas anneal only reduces the glass frit at the silicon/silver metal interface, or there is some form of hydrogenation during FGA, LBIC scans of some multi-crystalline cells before and after forming gas anneal in both RTP and CFP were carried out. In this study, three sets of samples comprising of String Ribbon and Cast multi-crystalline silicon from Eurosolare and Bayer were used. Set 1 samples were scanned before a forming gas anneal for 30 seconds in RTP. Set 2 was annealed in CFP for 15 minutes in forming gas ambient after scanning. While set 3 was annealed in RTP for 3 minutes after the LBIC scan. Figures 6a-6f show the LBIC scans for three cells fabricated on multi-crystalline silicon from Bayer, Evergreen and Eurolare, before and after a 30-second photo-assisted forming gas anneal.

As shown in figures $6 a$ to $6 \mathrm{f}$, the LBIC scans before and after FGA in RTP for only 30 seconds are similar in each case. Unlike the 30 second FGA, the LBIC scan before FGA is slightly different from the LBIC scan after 3-min FGA in RTP, Figs $7 \mathrm{a}$ and $7 \mathrm{~b}$. Similarly, there exist some slight differences between Figs. $8 a$ and $8 b$, the LBIC scans before and after FGA in CFP for 15 minutes. However, irrespective of the forming gas anneal time and process, the fill factor was observed to improve with reduced series resistance. This $L B I C$ response of the cells after either a 3-minute FGA in RTP or 15 minute in CFP is slightly inferior to that observed before the heat treatment. However, this effect does not show any appreciable degradation in cell performance.

The $J_{02}$ value from dark I-V analysis for cell EU2 was found to be $164 \mathrm{nA} / \mathrm{cm}^{2}$, which is an order of magnitude higher than that obtained for cell 2euo4-3 (Fig.3). This explains why the fill factor in this case is lower -0.719 . Also, for cell Bmc2 with 0.744 fill factor, the $J_{02}$ value was found to be $3569 \mathrm{nA} / \mathrm{cm}^{2}$ even though the shunt resistance was over $6 \mathrm{k} \Omega-\mathrm{cm}^{2}$. This value, however, is of the same order of magnitude for the slow fired cell bmc4-7 of Fig. 3. The String Ribbon (T7) also gave a high $\mathrm{J}_{02}$ value of $1240 \mathrm{nA} / \mathrm{cm}^{2}$. It should be pointed out here that the high saturation current density is not due to the short time of anneal but the quality of the material. On the other hand, cell Eu2-6 (the 15-minute CFP annealed cell in forming gas ambient), had a $J_{02}$ value of $1115 \mathrm{nA} / \mathrm{cm}^{2}$, which is three orders of magnitude higher than cell 2euo4 3 and a corresponding fill factor of 0.731 . However, the $\mathrm{J}_{02}$ value for the 3-minute photo-assisted annealed cell Eu2-9 was found to be $485 \mathrm{nA} / \mathrm{cm}^{2}$ and fill factor of 0.721 .

\section{CONCLUSION}

Screen-printing is widely used in Industry because it is simple, low-cost and rapid. However, cost and throughput gains are attained at the expense of performance. Fill factors of most commercial cells are in the range of 0.68 75 for single crystalline material. This paper shows that a rapid $400^{\circ} \mathrm{C} / 0.5-3 \mathrm{~min}$ photo-assisted anneal in a forming gas ambient can raise the fill factor (FF) of screen-printed
(SP) single and multi-crystalline $(\mathrm{mc})$ Si cells from $\sim 0.47$ to $\sim 0.77$ and 0.76 , respectively. This improvement is similar to the 15 minute FGA anneal in conventional furnace processing. Dark I-V analysis showed that this is the result of decrease in series resistance by a factor of 2 to 4. This allows the use of a gentler contact firing condition $\left(\geq 700^{\circ} \mathrm{C}\right)$ to prevent junction shunting, followed by a photo-assisted forming gas anneal to restore the low contact resistance and fill factor. The LBIC analysis showed that the very short time forming gas anneal in RTP is more beneficial than the extended time in conventional furnace tube. However, the slight difference observed before and after FGA in LBIC response of the cells did not show any appreciable degradation in cell performance.

\section{REFERENCE}

[1] K. Okamoto, T. nammori, T. Nunoi, T. Takemoto and T. Tsuji, "Rapid firing of printed pastes for BSF solar cell under high intensity light source" $16^{\text {th }}$ IEEE PVSC, 1982, pp. 818-823.

[2] G. C. Cheek, R. P. Mertens, R. Van Overstraeten and L. Frisson, "Thick film metallization for solar cell applications" IEEE Trans. On Electron Dev. Vol.ED-31, no.5, 1984, pp. 602-609.

[3] Sivoththaman, J. Horzel, W. Laureys, F. Deurinckx, P. De Schepper, J. Szlufcik, J. Nijs and R. Mertens, "Towards a fast and cost-effective production of industrial size silicon cells using rapid thermal processing and screen printing" $26^{\text {th }}$ IEEE PVSC, 1997

[4] S. Sivoththaman et al "High throughput processing of large area multi-crystalline silicon solar cells by RTP and SP" $2^{\text {nd }}$ WCPVSC, 1998, pp. 1970-1973.

[5] A. Rohatgi, S. Narasimha, A. Ebong, and P. Doshi, "Understanding and Implementation of Rapid Thermal Technologies for High Efficiency Silicon Solar Cells", IEEE Trans. On Electron Dev., 46 (10), 1999, pp. 1970-1977, [6] M. J. A. A. Goris et al., "Emitter Diffusion Using an IR Belt Furnace", $2^{\text {nd }}$ WCPVSC, 1998, pp. 1523-1526. 